\title{
Rule Based Fuzzy Indexing for Grading of proposed Industrial Sites for Power Plant Installation
}

\author{
Kalyani Sambhoo ${ }^{1}$, Sanjay Kadam ${ }^{2}$, Ashok Deshpande ${ }^{3}$ \\ ${ }^{1}$ Department of Computer Science, University of Pune, Maharashtra, INDIA, \\ Modern College of ASC, Pune-5, Maharashtra, INDIA, \\ Email: profkalyanis@gmail.com \\ ${ }^{2}$ Evolutionary Computing and Image Processing Group, Centre for Development \\ of Advanced Computing, Pune-7, Maharashtra, INDIA, \\ Email: sskadam@cdac.in \\ ${ }^{3}$ Berkeley Initiative Soft Computing, Special Interest Group, Environmental Management System, Berkeley, \\ USA, College of Engineering, Pune-5, Maharashtra, INDIA,
}

\begin{abstract}
The problem of site selection in an indefinite environment has gained overriding importance in recent years. In case of selection of a site for the construction of new hazardous power plants have attained significance due to a variety of reasons. The authors believe that the issue of site selection for an upcoming, say, a power plant installation based only on Environmental impact assessment (EIA) study could be inadequate. Therefore, there is a need to look beyond EIA process, and suggest poilcy makers a set of useful mathematical techniues with an objective to rank the sites for such installtions. EIA is aimed at identifying the possible impacts of Industrial development activities on the existing Environment. This method begins with initial screening to check if it may result in negative impacts on the Environment. Scoping determines which components to include in the initial screening phase. Many components considered in the process cannot be measured precisely (e.g., response to public involvement programs, willingness for resettlement, possible effects on economy, social acceptance etc.,). In order to process this vague and subjective information, we have applied Fuzzy Indexing with a Rule base to check the suitability of a site for Thermal, Hydroelectric, Nuclear and Gas based Power Plant installations and classify them as 'V. Good', 'Good', 'Fair' and 'Poor' and finally grade them.
\end{abstract}

Email:ashok_deshpande@hotmail.com

\section{Indexing terms/Keywords}

Environmental Impact Assessment, Scoping, Fuzzy Indexing, Fuzzy Rule Base

\section{cademic Discipline And Sub-Disciplines}

Computer Science

\section{SUBJECT CLASSIFICATION}

Softcomputing

\section{Council for Innovative Research}

Peer Review Research Publishing System

Journal: INTERNATIONAL JOURNAL OF COMPUTERS \& TECHNOLOGY

Vol 10, No 7

editor@cirworld.com

www.cirworld.com, member.cirworld.com 


\section{INTRODUCTION}

Human activity has been altering for betterment. Beginning several decades ago societies decided that they wanted a better understanding of human interactions with the environment[15]. Laws and regulations for Environmental protection have emerged due to this concern. The government authority as well as Environmental Experts require an efficient and unbiased tool for the evaluation of possible effects on the environment prior to the development process. Environmental impact assessment(EIA) has become a legislative requirement for more than three decades.

Irrespective of the geographical location of the site there are a number of EIA procedures that involve the attempt to measure social acceptance and possible effects after development which are not possible to be measured objectively. During this process technical experts are assigned the task to analyze and interpret the huge amount of data on ecosystem.

The proposed project could be an installation of a power plant, or setting up of any hazardous industrial unit at some site. The EIA methods require measurement of specific parameters and variables to estimate the values of impact factors or indicators[1]. These parameters and indicators, for example, may represent willingness for resettlement, response from public for an upcoming power plant, accessibility to community resources, response for public involvement programs, or impact on human health and economy.

The EIA process is an authoritarian requirement for businesses around the world for over decades, and has currently attracted significant research interests. Currently, addressing issues related to hazardous industrial installations has assumed vital importance across the globe. For example, the issues of rehabilitation, provision of safe drinking water, providing good infrastructural facilities, and studying the impact on human health are now being given serious consideration in the EIA process.

Scoping is the first stage in EIA that involves identification of social, cultural components that are relevant for decision making on the suitability of a particular site for power plant installation. Many a times an agreement is reached without consulting the investors. The existing Battelle Environmental Evaluation system(BEES)[1] assigns weights to each of the parameters, which depict the overall environment quality of a proposed site. These weights can be easily manipulated to portray the suitability of a site based on the convenience of the Proponent. This method is strongly opposed and considered to be inefficient as it does not have a convincing mathematical procedure.

There is a need of a full proof method for such decisions as an apposite choice of an Industrial site for upcoming power plants is an irreversible decision. A poor choice of site may lead to overheads such as increased cost of transportation, lack of skilled labor, poor infrastructural facilities or degradation of existing environmental conditions. On the other hand, the application of reliable and accurate methods for site selection may lead to efficient utilization of resources, reduced transportation cost, and satisfied stakeholders with minimal ill effects caused to the existing environment. Since societal values and ecological attributes cannot be measured objectively, the final decision statement may fail to depict the actual conditions.

Fuzzy multi-criteria decision analysis was applied for selection of Industrial area by recognizing certain nine important parameters for site selection such as slope, landuse, agriculture, fault, soil type. Informatsion layers were formed in the GIS environment[8]. Weights were assigned and weight layers were consolidated by conducting fuzzy Logic in GIS environment and the best places were identified for industrial areas. However, the work was not specific to any Power Plant installation and it did not consider all the important attributes to verify the suitability of the site with respect to Air, Water, Land, Socioeconomic and Ecological quality.

In an attempt to study the land suitability for Scientific Research reserves; a fuzzy logic based model was developed which was used to study the characteristics of a set of sites and compare them[3]. The method combined a fuzzy logic knowledge base with site specific data. It was not a generalized model and did not consider the suitability of these sites with respect to the other important attributes like Air, Water quality as well as did not consider the socioeconomic aspect.

In our opinion, the use of soft computing method would reduce the subjectivity aspect in the scoping phase of EIA and also address the imprecise nature of the governing parameters and impact indicators. In the present research work, we have implemented soft computing[21] method for site selection namely, Rule based Fuzzy Indexing.

Fuzzy Indexing has been used to rank the potential industrial sites. This has been done by calculating the product of the membership grade based on fuzzy sets for each parameter and the value of the corresponding triplets (that gives index for Air, Water, Land, Socioeconomic and Ecological attributes). The overall score has been computed as extended product of fuzzy numbers[5].

The paper is organized as follows: Section II describes the Methodology, where an overview of the methods used for ranking the industrial sites is discussed, Section III presents a Case study, Section IV presents Results and Discussion, and Section V presents Conclusions and Future work. 


\section{METHODOLOGY}

The method for ranking of sites for setting up hazardous industrial power plants has been briefly discussed

\section{Fuzzy Indexing}

The Fuzzy indexing method uses the Triangular membership function distribution comprising a four point scale pattern, i.e. Poor, Fair, Good and V. Good. The first number in the Triplet denotes the value at which the membership function is 1. The second and the third number in the triplet designate the distance to the left and right, respectively, of first number where the membership value is zero.

The values of the Triplets[5] are as follows: Poor[0 0 25], Fair[0 25 50], Good[25 50 75], Very Good[75 100 100]

Following are the steps to compute the rank of a Site based on different attributes. We give expressions only for the 'Air attribute. The expressions for the other attributes are similar.

1. The Site Index for each major attribute is calculated as the product of membership grades in Table 2 with the corresponding values of Triplets. For Air, the SIA (Site Index Air) is given as follows[5]

$\mathrm{SIA}=\Sigma \mu_{\mathrm{A}}{ }^{*} \mathrm{~T}$

where, $\mu_{\mathrm{A}}$ is a vector of membership grades of the attribute 'Air' and ' $T$ ' indicates the value of Triplets.

2. Calculate the preference or importance of each major attribute. The preference of importance QA for 'Air' attribute is computed as follows:

$\mathrm{QA}=\Sigma \mathrm{R}^{*} \mathrm{~T}$

where, ' $R$ ' represents a vector of relative weightages as shown in Table 3 and ' $T$ ' is the value of Triplets.

3. Normalize the triplets of preference (for each attribute) by dividing each by Qsum. The Qsum is sum of the first components of QA (Air), QW (Water), QL (Land), QS (Socioeconomic), and QE (Ecological). For the 'Air' attribute, the normalized value $Q A$ rel is given by

QArel = QA / Qsum

4. The overall score of a Site SO1 is given as

SO1 $=S I{ }^{*} Q A r e l+S I W * Q W r e l+S I{ }^{*} Q$ Lrel + SIS * QSrel + SIE * QErel

Here, SIA, SIW, SIL, SIS, SIE are the site Index values for major attributes Air, Water, Land, Socioeconomic and Ecological and QArel, QWrel, QLrel, QSrel and QErel represent the relative weightages of the criteria or the relative weighted Triplets as calculated in Step 3.

The extended sum and product is calculated as

$(a b c) *(d e f)=(a d \quad a e+d b a f+d c)$

where, "*' represents extended product of two fuzzy numbers, and + represents the extended sum of two fuzzy numbers.

The product of membership grade calculated based on fuzzy sets for each parameter and value of Triplets gives the Index for Air, Water, Land, Socioeconomic and Ecological attributes. In a similar way, Triplets for individual preference to the importance of each criterion can be created. The overall score can be computed as extended product of the fuzzy numbers.

5. The overall score $X$ is calculated by considering horizontal distance of centriod of a triangle from its origin. The overall quality which is expressed by the Triplet $(a b c)$ can be represented by a triangle ABC

The first digit of the Triplet gives an idea about the quality or suitability of the site. The higher the value, the better is the suitability. The overall score $\mathrm{X}$ is calculated as:

$\mathrm{X}=\mathrm{a}-((\mathrm{b}-\mathrm{c}) / 3)$

\section{CASE STUDY}

In the case study we use the above-mentioned method to grade different sites for setting up hazardous industrial power plants based on various attributes. The candidate sites for the set up of Thermal, Hydroelectric, Nuclear and Oil/Gas based Power Plants are considered in this research work. The data required for the grading of the sites is available in the form of Environmental Impact Assessment Reports[4,6,7,10,11,12,13,16,17,19,20]. Table 1 shows some of the numeric data for the five sites proposed for Thermal Power Plant.

The major attributes which have been used in the study include Air, Water, Land, Socioeconomic and Ecological. These attributes in turn comprise sub-attributes. For example, Air has sub-attributes such as $\mathrm{CO}$ (Carbon Monoxide), NOx(Nitrogen/Nitrides ), SOx(Sulphur Dioxide)and Ozone which depict Air quality. 
Some of the important attributes of Air quality considered in our study are nitrogen dioxide if inhaled in excess leads to respiratory problems. Nitrogen dioxide inflames the lining of the lungs, and it can reduce immunity to lung infections. This can cause problems such as wheezing, coughing, colds, flu and bronchitis. Increased levels of nitrogen dioxide can have significant impacts on people with asthma because it can cause more frequent and more intense attacks. Another important pollutant considered in our study is Sulphur dioxide, in excess it affects human health when it is breathed in. It irritates the nose, throat, and airways to cause coughing, wheezing, shortness of breath, or a tight feeling around the chest.

So, it is very essential to select a site which is away from thickly populated locations. This is also one of the important parameters considered for ranking of sites. It is also further verified that all the parameters for Air and water quality also comply to the standards specified by Central Pollution Control Board, INDIA[2] and Ministry of Environment and Forest[9] else the site is classified as 'Poor' or unsuitable.

Table 1: Sub attributes for Thermal Power Plant

\begin{tabular}{|c|c|c|c|c|c|}
\hline Attributes & $\begin{array}{l}\text { Site 1- } \\
\text { Badarpur, } \\
\text { Delhi }\end{array}$ & $\begin{array}{l}\text { Site 2 - } \\
\text { Amreli, } \\
\text { Gujarat }\end{array}$ & $\begin{array}{l}\text { Site } 3 \text { - } \\
\text { Bharuch, } \\
\text { Gujarat }\end{array}$ & $\begin{array}{l}\text { Site 4- } \\
\text { Tutocorin, } \\
\text { TamilNadu }\end{array}$ & $\begin{array}{l}\text { Site5- } \\
\text { Khammam, } \\
\text { Andhra } \\
\text { Pradesh }\end{array}$ \\
\hline \multicolumn{6}{|l|}{ Air } \\
\hline $\mathrm{CO}($ in $\mu \mathrm{g} / \mathrm{m} 3)$ & 11.0 & 14.6 & 15.0 & 18.0 & 17 \\
\hline $\mathrm{NOx}$ (in $\mu \mathrm{g} / \mathrm{m} 3$ ) & 15.7 & 8.4 & 40 & 14 & 9.35 \\
\hline $\mathrm{SO}_{2}$ (in $\mu \mathrm{g} / \mathrm{m} 3$ ) & 9.8 & 7.6 & 50 & 8.5 & 7.8 \\
\hline $\begin{array}{l}\text { RSPM/PM } 10 \\
\mu \mathrm{g} / \mathrm{m} 3 \text { ) }\end{array}$ & 122.6 & 101.1 & 4 & 55.0 & 30.75 \\
\hline $\mathrm{PM}_{2.5}$ & 47.5 & 33.9 & 17.5 & 12 & 18.15 \\
\hline \multicolumn{6}{|l|}{ Water } \\
\hline $\mathrm{Ph}$ & 7.8 & 7.6 & 8.0 & 7.98 & 7 \\
\hline TotColiform (in mg/m3) & 100 & 24.6 & 110 & 100 & 110 \\
\hline $\mathrm{DO}(\mathrm{mg} / \mathrm{l})$ & 4.25 & 4.5 & 5.2 & 5.4 & 8 \\
\hline $\mathrm{BOD}(\mathrm{mg} / \mathrm{l})$ & 2.4 & 1.6 & 1.7 & 4 & 3 \\
\hline
\end{tabular}

The subatributes considered for Air and Water quality of Thermal Power plant is depicted in Table 1.Similarly, data for Land quality, Ecological attributes and socioeconomic aspect was considered for other types of Power plants such as Hydroelectric, Nuclear and Oil/Gas based Power Plants.

Table 2: Membership Grades for major attributes for Thermal Power Plant

\begin{tabular}{|l|r|r|r|r|}
\hline Criteria & Poor & Fair & Good & VGood \\
\hline Air & & & & \\
\hline Site 1 - Badarpur & 0 & 0 & 0.9 & 0 \\
\hline Site 2 - Amreli & 0 & 0 & 0.9 & 0 \\
\hline Site 3 - Bharuch & 0 & 0 & 0.9 & 0 \\
\hline Site 4 - Tutocorin & 0 & 0 & 0 & 1 \\
\hline Site 5 - Khammam & 0 & 0 & 0.9 & 0 \\
\hline & & & & 0 \\
\hline Water & 0 & 0 & 0.9 & 0 \\
\hline Site 1 - Badarpur & 0 & 0 & 1 & 0 \\
\hline Site 2 - Amreli & 0 & 0 & 0.9 & 0 \\
\hline Site 3 - Bharuch & 0 & 0 & 0.9 & 0.9 \\
\hline Site 4 - Tutocorin & 0 & 0 & 0.9 & 0 \\
\hline Site 5 - Khammam & & & & 0 \\
\hline & & & & 0 \\
\hline Land & & & & 0 \\
\hline
\end{tabular}




\begin{tabular}{|l|r|r|r|r|}
\hline Site 1 - Badarpur & 0 & 1 & 0 & 0 \\
\hline Site 2 - Amreli & 0 & 0 & 1 & 0 \\
\hline Site 3 - Bharuch & 0 & 0 & 0 & 1 \\
\hline Site 4 - Tutocorin & 0 & 0 & 0 & 1 \\
\hline Site 5 - Khammam & 1 & 0 & 0 & 0 \\
\hline & & & & \\
\hline Socioeconomic & & & & \\
\hline Site 1 - Badarpur & 0 & 1 & 0 & 0 \\
\hline Site 2 - Amreli & 0 & 0 & 1 & 0 \\
\hline Site 3 - Bharuch & 0 & 0 & 0 & 1 \\
\hline Site 4 - Tutocorin & 0 & 0 & 0 & 1 \\
\hline Site 5 - Khammam & 0 & 1 & 0 & 0 \\
\hline & & & & \\
\hline Ecological & 0 & & & \\
\hline Site 1 - Badarpur & 0 & 0 & 1 & 0 \\
\hline Site 2 - Amreli & 0 & 0 & 0 & 1 \\
\hline Site 3 - Bharuch & 0 & 0 & 0 & 1 \\
\hline Site 4 - Tutocorin & 0 & 0 & 0 & 1 \\
\hline Site 5 - Khammam & 0 & 0 & 1 & 0 \\
\hline
\end{tabular}

Table 2 shows the Fuzzy values assigned to the inputs or sub-attributes (9 numeric and 12 descriptive) based on the fuzzy membership grades assigned to their corresponding major attributes (i.e., Air, Water, Land, Socioeconomic and Ecological).

A Fuzzy Rule base was developed after consulting Experts. Forty five rules for Air Quality with important sub-attributes $\mathrm{CO}, \mathrm{SO} 2, \mathrm{NO}_{2}$ and $\mathrm{PM}_{10}$ and Sixteen for Water quality were considered to assign the membership grades which are shown in Table 2. Each sub-attribute like; $\mathrm{SO}_{2}$ (Air) had the classes 'V.Good', 'Good' , 'Fair' and 'Poor' for specific range of input values. The range 10 to 40 (in $\mu \mathrm{g} / \mathrm{m} 3$ ) indicates the class 'V. Good', the range 30 to 70 indicates the class 'Good', the range 60 to 100 indicates the class 'Fair' and the class 80 to 130 indicates the class 'Poor'.

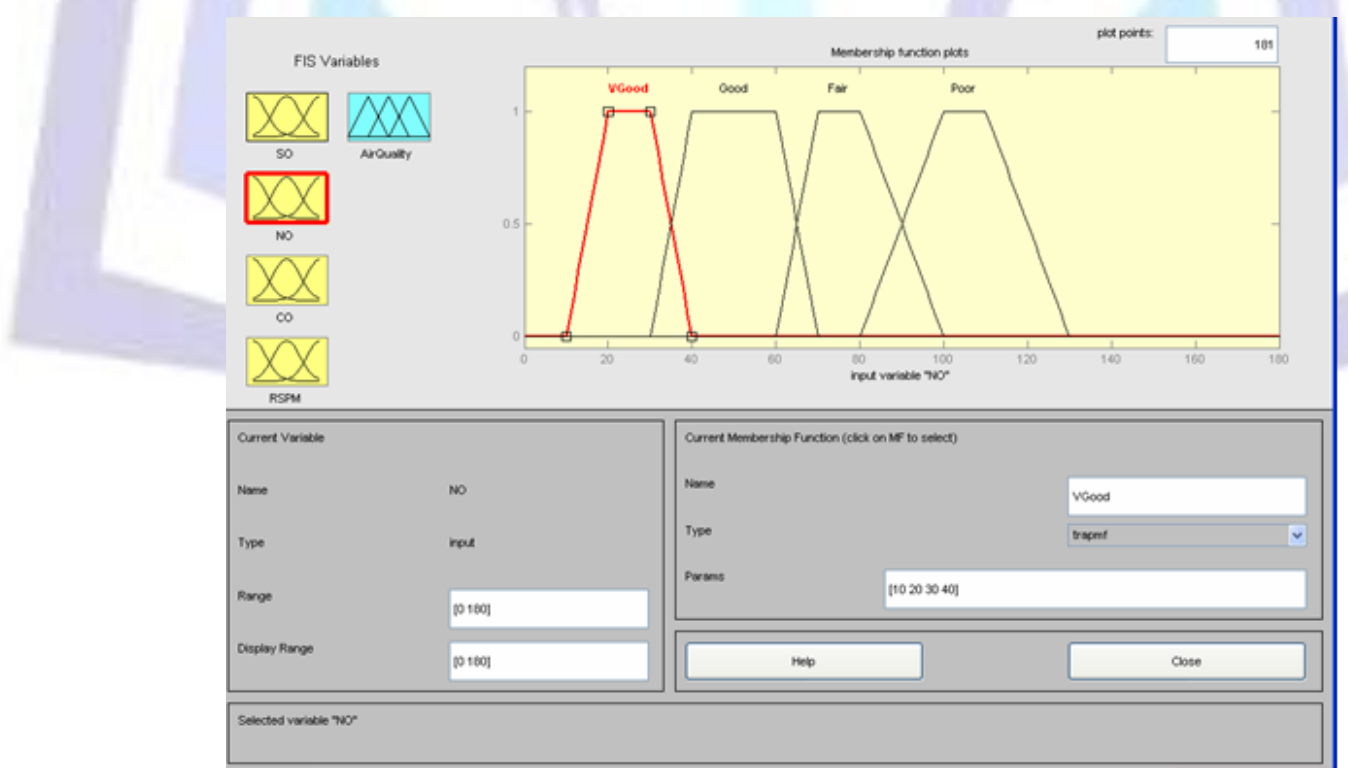

Figure 1: Membership functions for $\mathrm{SO}_{2}$

Figure 1shows the classes 'V.Good', 'Good', 'Fair' and 'Poor' for one of the sub-attribute for Air, namely, NOx.

Similarly, Fuzzy sets for other subattributes of Air and Water were prepared after consulting Environmental Experts. 


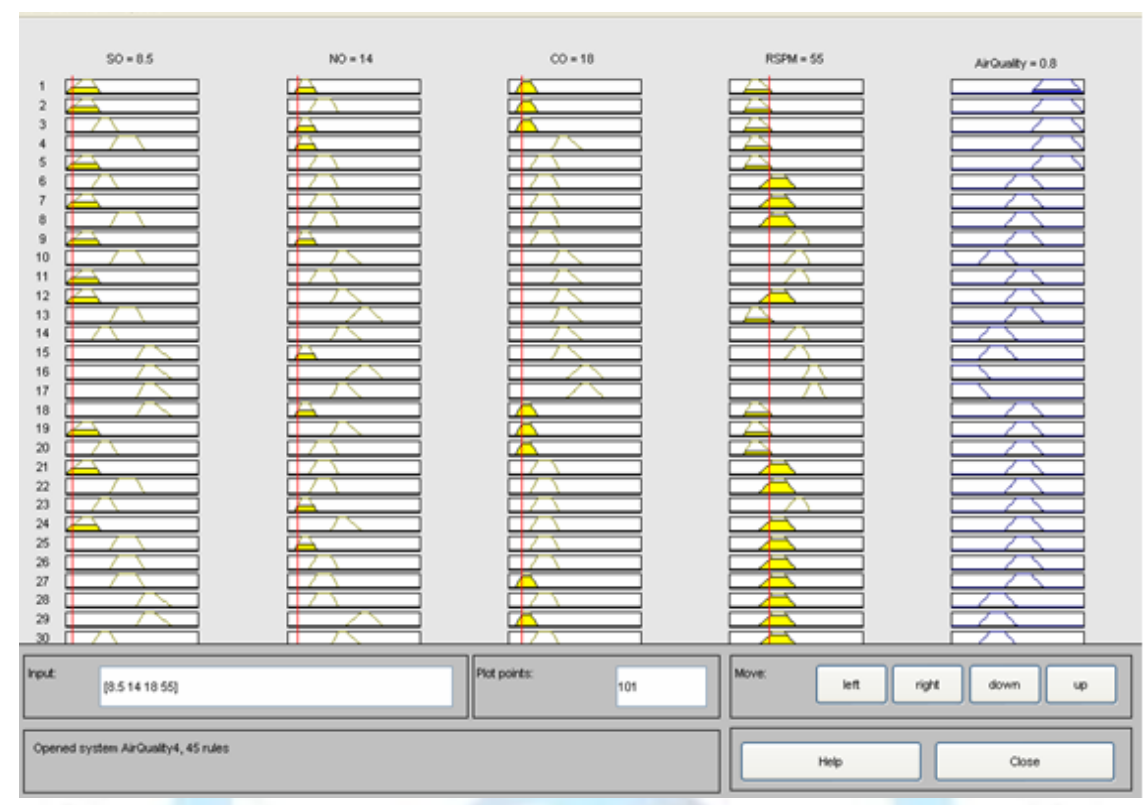

Figure 2: Rule Viewer

The execution of the Rule base is as shown in the Figure.2; for a certain set of input. The actual values are entered in the input box, the rules are then fired the output shows a value of '0.8' after the execution of all the rules for Air quality. All the sub-attributes in the rule are aggregated with an 'AND' operation. All the rules carry equal weights or importance. This output value obtained after the execution of rules is mapped to the output.

The fuzzy rule base was applied to get the overall Air quality.

An example of a rule is as follows: 1. If (SO is VGood) and (NO is VGood) and (CO is VGood) and (RSPM is VGood) and (PM10 is VGood) then (AirQuality is VGood). The output was a membership grade which maps to one or two of the output classes considered in this work.

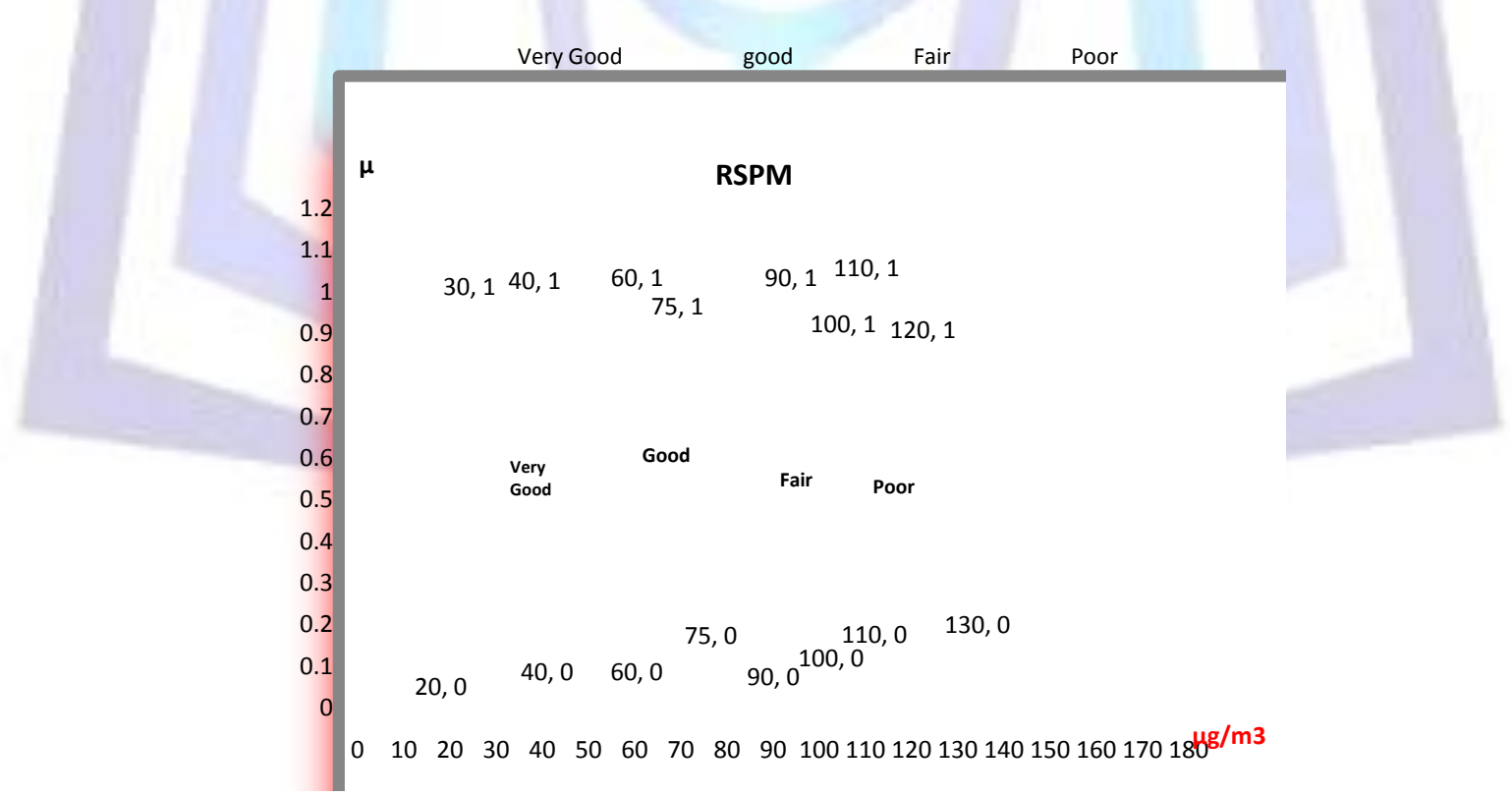

\section{Figure 3: Fuzzy set for RSPM}

Figure 3 shows the classes for RSPM(Respirable suspended Particulate matter)in Air 


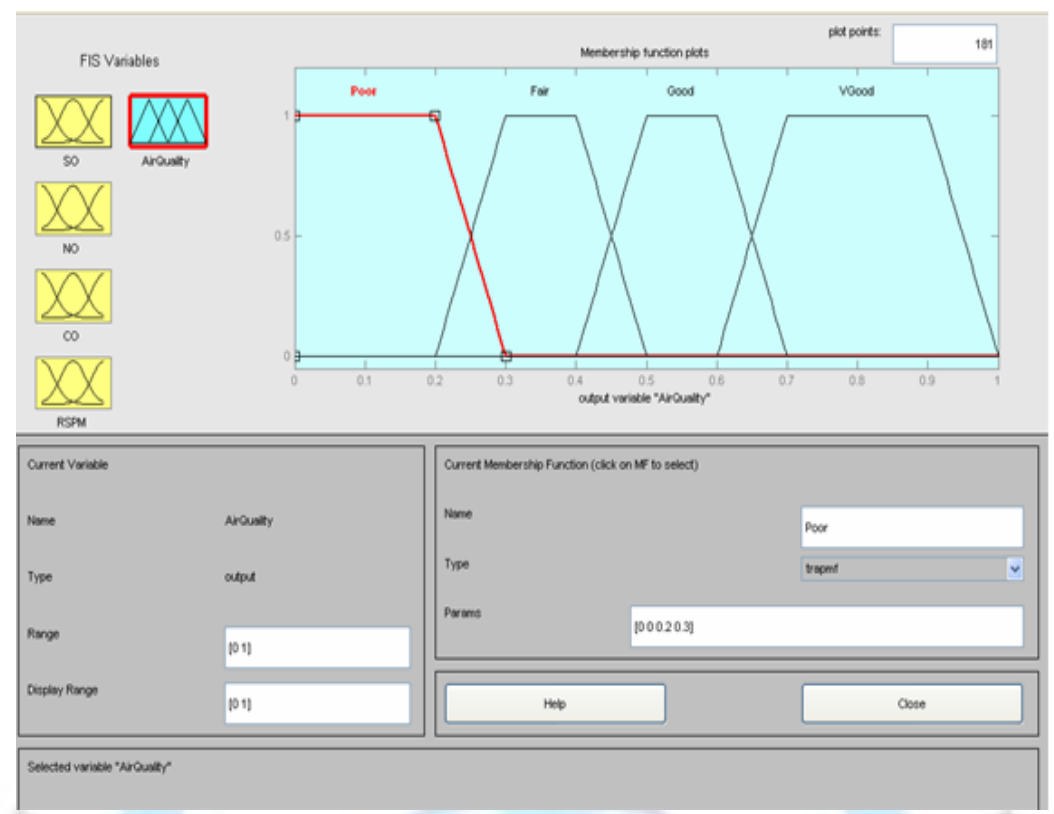

Figure 4: Membership functions for Air Quality

Figure 4 depicts the membership grade for overall Air Quality after considering the fuzzy membership grades of each subattributes and after firing the forty five Rules.

Similary, a rule base for water quality is also created with main sub-attributes as BOD, DO, pH andTotal Coliforms with their respective permissible range to get the membership grades for overall water quality for the classes for all types of Power plants.

Other linguistic attributes considered for Land or location suitability include: willingness for resettlement, suitable infrastructure, proximity to water source, unloading space, transport facility, land away from sanctuaries, thick population, seacoast regulations. Socioeconomic aspect considers effects on human health, and economy, legal rights, access to community services, household facilities, public involvement programs, response from public. Ecological aspect considers: adequate sunlight, latitude, altitude and chances of fire.

To assign weights to each of the main attributes we apply the Rank Order Centroid technique.

$\mathrm{W}_{\mathrm{i}}=(1 / \mathrm{M}) \sum_{\mathrm{n}=\mathrm{i}}^{\mathrm{M}} 1 / \mathrm{N}$

Where, ' $M$ ' is the number of items and $W_{i}$ is the weight for the ith item. The importance order received from Experts is given as below. By applying (7) the weights are computed as below:

\section{Main Attribute}

Air Quality

Water Quality

Land Quality

Ecological Quality

Socioeconomic

\section{Importance}

1

2

3

4

5

Table 3: Preference or importance given for Criteria

\begin{tabular}{|l|r|r|r|r|}
\hline Attributes & Poor & Fair & Good & V. Good \\
\hline Air & 0 & 0 & 0 & 0.36 \\
\hline Water & 0 & 0 & 0 & 0.26 \\
\hline Land & 0 & 0 & 0 & 0.16 \\
\hline Socioeconomic & 0 & 0 & 0 & 0.09 \\
\hline Ecological & 0 & 0 & 0 & 0.04 \\
\hline
\end{tabular}


The triangular membership function is represented by a set of three numbers called as 'Triplets'. The first number of 'Triplet' denotes the value at which the membership function is 1 . The second and the third number of the triplet designate the distance to the left and right, respectively, from the first number, where the value of membership function is 0 .

Table 4: Values of the triplets[5]

\begin{tabular}{|l|r|r|r|}
\hline Attributes & $\begin{array}{r}\text { Number } \\
\text { where MF=1 }\end{array}$ & & \\
\hline Poor & 0 & 0 & 25 \\
\hline Fair & 0 & 25 & 50 \\
\hline Good & 25 & 50 & 75 \\
\hline V. Good & 75 & 100 & 100 \\
\hline
\end{tabular}

We now discuss the application of Fuzzy indexing used for ranking of the sites. The following steps describe the detailed calculations in accordance to the method discussed in Section II. We describe calculation performed for each of these sites.

\section{Fuzzy indexing calculations for Site 1}

We present a detailed description to compute the rank of Site 1 (Badarpur). The calculations for the other sites can be performed by similar method.

Step 1: The site index for Air quality (SIA) is calculated as the sum of the products of the membership grades (Table 2) with the values of the triplets (Table 4). It is given as (Eqn. 1):

$$
\begin{aligned}
\mathrm{SIA}= & 0\left(\begin{array}{lll}
0 & 0 & 25
\end{array}\right)+0\left(\begin{array}{lll}
0 & 25 & 50
\end{array}\right)+0.9\left(\begin{array}{ll}
25 & 50 \\
& 75)+0\left(\begin{array}{lll}
75 & 100 & 100
\end{array}\right) /(0+0+0.9+0
\end{array}\right) \\
= & \left(\begin{array}{lll}
25.0 & 50.0 & 75.0
\end{array}\right)
\end{aligned}
$$

Similarly, we can calculate the site index for other major attributes like SIW (for Water), SIL (for Land), SIS (for Socioeconomic) and SIE (for Ecological).

Step 2: We next calculate the preference or importance of each major attribute. The detailed calculations (Eqn. 2) for 'Air' attribute are as given as follows (Refer Table $3 \&$ Table 4)

$$
\begin{aligned}
Q A= & 0\left(\begin{array}{lll}
0 & 0 & 25
\end{array}\right)+0\left(\begin{array}{lll}
0 & 25 & 50
\end{array}\right)+0\left(\begin{array}{ll}
25 & 50 \\
& 75)+0.36\left(\begin{array}{lll}
75 & 100 & 100
\end{array}\right) /(0+0+0+0.36
\end{array}\right) \\
= & \left.\begin{array}{lll}
75.0 & 100.0 & 100.0
\end{array}\right)
\end{aligned}
$$

The preference of importance QW (Water), QL (Land), QS (Socioeconomic) and QE (Ecological) for other attributes can similarly be calculated using the above method.

Step 3: We then take sum of the first value of all the triplets obtained in Step 2 and denote it by Qsum. We normalize the triplets of preference (for each attribute) by dividing each by Qsum (Eqn 3). For example, the calculations for the 'Air' attribute (represented by QArel), with a Qsum $=375$, are depicted as follows:

QArel $=Q A / 375$

$$
=\left(\begin{array}{lll}
0.2 & 0.27 & 0.27
\end{array}\right)
$$

Similarly, we calculate triplets for other major attributes. QWrel (Water), QLrel (Land), QSrel (Socioeconomic) and QErel (Ecological).

Step 4: Therefore, the overall score SO1 for Site 1 can be computed as extended product of the fuzzy numbers as follows (Eqn. 4):

$$
\begin{aligned}
\text { SO1 }= & \text { SIA }^{*} \text { QArel }+ \text { SIW }^{*} \text { QWrel }+ \text { SIL }^{*} \text { QLrel }+ \\
& \text { SIS * QSrel }+ \text { SIE * QErel } \\
= & {\left[\begin{array}{llc}
45.0 & 130.0 & 145.0
\end{array}\right] }
\end{aligned}
$$

Step 5: We compute the centroid (for defuzzified value) which gives the defuzzified value XS1 for Site 1:

$$
\mathrm{XS} 1=50.0
$$




\section{Fuzzy indexing calculations for other sites:}

Using similar method as described for Site 1, we can compute the extended products and defuzzified values for other sites. The results for Site 2 (SO2 and XS2), Site 3 (SO3 and XS3), Site 4 (SO4 and XS4) and Site 5 (SO5 and XS5)respectively, are depicted below:

\begin{tabular}{|c|c|c|}
\hline $\mathrm{SO} 2=[25.0$ & 73.33 & 88.33] \\
\hline \multicolumn{3}{|l|}{$X S 2=30.0$} \\
\hline $\mathrm{SO} 3=[40.0$ & 108.33 & 118.33] \\
\hline \multicolumn{3}{|l|}{$X S 3=43.33$} \\
\hline SO4 $=[65.0$ & 176.67 & 181.67] \\
\hline \multicolumn{3}{|l|}{$X S 4=66.67$} \\
\hline SO5 $=[15.0$ & 55.00 & 80.0] \\
\hline$X S 5=23.33$ & & \\
\hline
\end{tabular}

The ranking of sites can be done in the descending order of XSi values $(i=1,2,3,4,5)$. The higher the value of XSi, more is the suitability or rank of the site for setting up of hazardous industrial power plants. In the present case study, the individual sites had the following ranking (in descending order of their ranks):

The sites for Thermal Power Plants are ranked as -

$\begin{array}{llc}\text { Site Name } & \text { Score } & \text { Grade } \\ \text { Site 4 (Tutocorin) } & 66.67 & 1 \\ \text { Site 1 (Badarpur) } & 50.0 & 2 \\ \text { Site 3 (Bharuch) } & 43.33 & 3 \\ \text { Site 2 (Amreli) } & 30.0 & 4 \\ \text { Site 5 (Khammam) } & 23.33 & 5\end{array}$

The results obtained for Hydroelectric Power Plant were as follows:

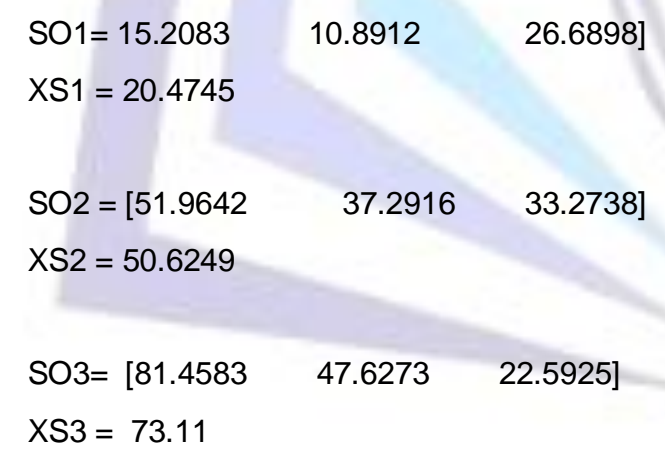

The sites for Hydroelectric Power Plants are ranked as -

\section{Site Name}

Site 3 (Sikkim)

Site 2 (Himachal Pradesh)

Site 1 (Arunachal Pradesh)

\section{Score Grade}

$\begin{array}{ll}73.11 & 1 \\ 50.6249 & 2 \\ 20.4745 & 3\end{array}$

The results obtained for Nuclear Power Plant were as follows:

$$
\begin{aligned}
& \text { SO1 }=\left[\begin{array}{lll}
55.0 & 153.33 & 163.33
\end{array}\right] \\
& X S 1=58.33
\end{aligned}
$$




$$
\begin{aligned}
& \mathrm{SO} 2=\left[\begin{array}{lll}
30.0 & 95.0 & 115.0
\end{array}\right] \\
& \mathrm{XS} 2=36.67
\end{aligned}
$$

The sites are ranked as -

\section{Site Name}

Site 1 (Jaitapur)

Site 2 (Kundallam)

\section{Score}

58.33

36.67

\section{Grade}

1

2

The results obtained for Gas based Power Plants were as follows:

$$
\begin{aligned}
& \text { SO1 }=\left[\begin{array}{lll}
35.0 & 106.67 & 121.67
\end{array}\right] \\
& \mathrm{XS} 1=40.0 \\
& \mathrm{SO} 2=\left[\begin{array}{lll}
55.0 & 53.33 & 163.33
\end{array}\right] \\
& \mathrm{XS} 2=91.67
\end{aligned}
$$

The sites for Gas based Power Plants are ranked as -

\section{Site Name}

Site 2 (Shadol)

Site 1 (Patan)

\section{Score}

91.67

40.0
Grade

1
2

The ranks computed by the Fuzzy Indexing method and those computed by the existing method concur with each other. In the Fuzzy Indexing method many of the non-numeric attributes were also considered to enhance the accuracy of the method in comparison to the existing methods.

\section{RESULTS AND DISCUSSION}

Table 5 shows the results obtained by applying a Rule based Fuzzy Indexing method in the absence of a standard mathematical model for Ranking of such sites. Fuzzy Logic[21] proved to be a useful tool to handle imprecise and linguistic information. The method considers the partial memberships of each of the sub-attributes, which represent the actual situation.

Table 5: Ranking of sites by Rule based Fuzzy Indexing

\begin{tabular}{|l|c|}
\hline Sites & Fuzzy Indexing \\
\hline Thermal Power Plant & II \\
\hline Site 1 (Badarpur, Delhi) & IV \\
\hline Site 2 (Amreli, Gujarat) & III \\
\hline Site 3 (Bharuch, Gujarat) & I \\
\hline Site 4 (Tutocorin, Tamilnadu) & V \\
\hline Site 5 (Khammam, Andhra Pradesh) & II \\
\hline Hydro electric Power Plant & III \\
\hline Site 1 (Arunachal Pradesh) & I \\
\hline Site 2 (Himachal Pradesh) & I \\
\hline Site 3 (Sikkim) & II \\
\hline Nuclear Power Plant & II \\
\hline Site 1(Jaitapur, Maharashtra) & \\
\hline Site 2(Kundallum, Tamilnadu) & \\
\hline Oil/Gas Power Plant & \\
\hline Site 1(Patan,Gujarat ) & I \\
\hline Site 2(Shahdol, Madhya Pradesh) & \\
\hline
\end{tabular}


A total of nine numeric and thirteen non-numeric attributes have helped to accurately portray the existing environmental conditions by understanding the quantitative description provided in the EIA reports. The assignment of fuzzy membership grades and the value or weight age of different components with respect to Air, Water, Land, Socioeconomic, and Ecological quality have helped in comparing the existing alternative sites objectively and precisely by including the most important parameters in the assessment process. This distinguishes our approach with the previous attempts discussed in this paper.

The results obtained from our work are unbiased. The assignment of weights and final ranking follows a formalized mathematical procedure. These methods rule out the possibility of manipulation of the result or EIA report to suit the selfish motives of the proponents. Some of the sites considered in our work are in the initial development phase of the power plants and the rest are waiting for final decisions after some legal disputes.

\section{CONCLUSIONS AND FUTURE WORK}

Decision making is a complex issue and needs careful study as it involves the participation of all the stakeholders including a common man. Therefore the study of ground realities and continued dialogue with the likely affected population due to installation of a new facility is a must. Public hearing is one such aspect that needs to be strengthened. As there exists objective and subjective information-soft computing, a new kind of formalism in decision making is suggested.

The paper presented Rule based Fuzzy Indexing method for classification and ranking sites for setting up of Thermal, Nuclear, Hdroelectric and Gas based power plants. In Future work, an attempt would also be made to extend the approach with a Neuro-Fuzzy model, which would embed the linguistic description of parameters, and partial membership values in fuzzy sets (i.e., 'V. Good', 'Good', 'Fair' and 'Poor').

We propose to apply softcomputing techniques in Life Cycle Assessment which is our next cutting edge towards innovation.

\section{REFERENCES}

[1]Bindu N Lohani, J Warren Evans, Robert R. Everitt, Harvey Ludwig, Richard A. Carpenter, Shih Liang Tu, 1997, Environmental Impact Assessment for developing countries in Asia, Asian Development Bank

[2]Central Pollution Control Board, 2012, Government of India

[3]David M. Stoms, Jennifer M. McDonald, Frank W. Davis, 2002, Fuzzy Assessment of Land suitability for Scietific Research Reserves, Environmental ManagementVol 29, pp 545-558

[4]EIA, Nuclear Power Project Jaitapur, 2010, National Environmental Engineering Research Institute, Nagpur

[5]H. Das, 2005, Food Processing Operation Analysis, Asian Books Private Limited, pp. 383-394

[6]Kudankulam Nuclear Power Project, 2011, Nuclear Power Corporation Ltd

[7]Matrix Thermal Power Pvt Ltd, 2010, Report on Coal based washery based Thermal Power Plant, Khammam, Andhra Pradesh

[8]Mehdi Ziaei, Fatemeh hajiz adeh, Seid Said Reza Ahmadizadeh, Komeil Jahanifar, 2010, A combined model of GIS and Fuzzy multicriteria decision analysis for suitable evaluation/ selection of Industrial areas, Recent Researches in Environmental Science and Landscaping

[9]Ministry of Environment and Forest (MoEF), Guide lines for Industries and Impact Assessment, 2011

[10]Narmada Thermal Power Limited, 2011, Draft Environmental Impact Assessment Report for Thermal Power Plant, Bharuch, Gujarat

[11]National Environmental Engineering Research, 2012, Jaitapur

[12]NTPC Limited, 2010, Badarpur Combined Cycle Power Project, Badarpur, Delhi

[13]Patel Energy Limited, 2011, Draft Environmental Impact Assessment for coal based Thermal Power Plant, Amreli, Gujarat

[14]Ren Feng, 2010, Optimal site selection for Thermal Power Plants based on Rough sets and Multiobjective programming, E-Product E-Service and E-Entertainment (ICEEE)

[15]Richard B. Shepherd, 2005, Quantifying Environmental Impact Assessments using Fuzzy Logic, Springer

[16]R.S Envirolink Technologies, GMR Bajoli Holi Hydro Power Plant, 2010, Environmental Impact Assessment Report

[17]R.S Envirolink Technologies, TT Energy, 2010, Environmental Impact Assessment of H.E Project.

[18]S. Kaliraj, V.K Malar, 2012, Geospatial analysis to assess the potential site for coal based Thermal Power station in Gujarat, India, Advances in applied Science Research, pp 1554-1562

[19]Smec India, SEW Nafra Corporation, 2009, Environmental Impact Assessment and Environmental Management Plan for NAFRA Hydro Electric Power Project 
[20]SPIC Electric Power corporation Pvt. Ltd, 2010, HW Tuticorin Thermal Power Project, Tuticorin, Tamilnadu [21]Timothy J Ross, 1995, Fuzzy Logic with Engineering application, New Mexico, McGraw Hill

\section{Author' biography with Photo}

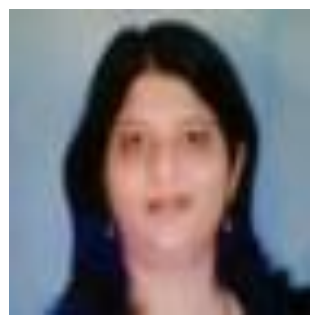

Kalyani Sambhoo is a Ph.D student at the Department of Computer Science, University of Pune, Maharashtra, INDIA. She is also working as an Assistant Professor at the Department of Computer Science, Modern College, Pune. She has a MPhil (Computer Sc), YCMOU and MCS (Computer Science), Pune University. Her research interests include Fuzzy Logic and Neural Networks.

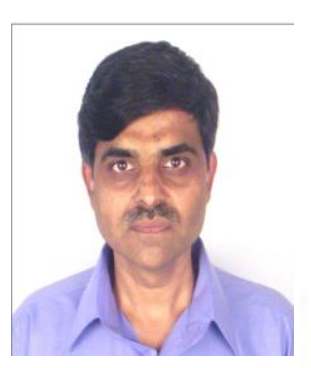

${ }^{2}$ Dr. Sanjay Kadam works as a Joint Director-ECIP in the Evolutionary Computing and Image Processing Group at C-DAC, Pune, India. He has a Ph.D. in Computer Science from the University of London, UK, an M.Tech in Computer Science from Indian Institute of Technology (IIT), New Delhi, and an M. Sc in Mathematics from Pune University. His research interests include Computer Vision and Image Processing, Neural Networks, Parallel Processing, Fuzzy Computing, Web Technology, and Software Engineering

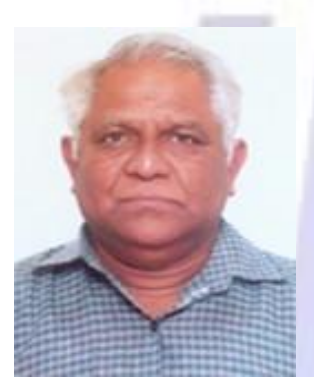

${ }^{3}$ Dr. Ashok W. Deshpande has a Ph. D (Engineering and Technology), Nagpur University, India Master of Engineering (Civil with Specialization in Environmental Engineering),

University of Roorkee, India, Graduate in Civil Engineering Affiliations (present)

Chair: Berkeley Initiative in Soft Computing (BISC) -Special Interest Group (SIG)- Environment Management Systems (EMS),University of California, Berkeley, California USA Guest Faculty: University of California, Berkeley (UCB) California USA

Guest Scientist : Lawrence Berkeley National Laboratory, Berkeley California USA Hon. Adjunct Professor in Bioinformatics: University of Pune (UoP), India Adjunct Professor: College of Engineering , Pune India Visiting Scientist: Bhabha Atomic Research Center (BARC) Mumbai India Former Deputy Director: National Environmental Engineering Research Institute (NEERI) India 